\title{
Análise e modelação matemática da interação entre partículas na filtração direta utilizando a teoria coloidal
}

\author{
Mathematical modeling and analysis of the particle interactions \\ in the direct filtration using the colloidal theory
}

\begin{abstract}
Alexandre Botari
Engenheiro Civil. Licenciado em Ciências Exatas - Matemática. Doutor em Engenharia Civil. Professor Adjunto da Universidade Estadual de Maringá (UEM)
\end{abstract}

- Umuarama (PR), Brasil.

Luiz Di Bernardo

Engenheiro Civil. Doutor em Engenharia Civil. Professor Titular do Departamento de Hidráulica e Saneamento da Escola de Engenharia de São Carlos Universidade de São Paulo (USP) - São Carlos (SP), Brasil.

\section{Angela Di Bernardo Dantas}

Engenheira Civil. Doutora em Engenharia Civil. Professora da Universidade de Ribeirão Preto (UNAERP) - Ribeirão Preto (SP), Brasil.

\section{Resumo}

Este trabalho utilizou a teoria coloidal para descrever o comportamento físico pelo balanço de forças e balanço de energia de complexos coloidais na água bruta e daqueles formados durante a filtração direta em escoamento ascendente. Nele são descritos os perfis de energia de interação entre as superfícies dos colóides para três geometrias: esférica, plana e cilíndrica; e quatro arranjos de interação entre as superfícies: dois cilindros, dois planos, duas esferas e uma esfera e um plano. Duas situações foram analisadas, antes e após a desestabilização eletrostática pela ação de sulfato de alumínio em águas de estudo contendo caulinita, utilizando-se a modelação e análise pela teoria DLVO (das iniciais de Derjarguin-Landau-Verwey-Overbeek) modificada, ou XDLVO, que inclui à abordagem tradicional das forças da dupla camada elétrica (DCE), forças de atração de superfície ou London-van der Waals (LvdW), forças estéricas, força hidrofóbica e forças de outras origens no cálculo do balanço de forças, a saber: repulsão molecular, denominada repulsão de Born, e a força oriunda das funções químicas Ácido e Base (AB) de Lewis.

Palavras-chave: modelação matemática; filtração direta ascendente; teoria coloidal; teoria XDLVO.

\section{Abstract}

This work used the colloidal theory to describe forces and energy interactions of colloidal complexes in the water and those formed during filtration run in direct filtration. Many interactions of particle energy profiles between colloidal surfaces for three geometries are presented here in: spherical, plate and cylindrical; and four surface interactions arrangements: two cylinders, two spheres, two plates and a sphere and a plate. Two different situations were analyzed, before and after electrostatic destabilization by action of the alum sulfate as coagulant in water studies samples prepared with kaolin. In the case were used mathematical modeling by extended DLVO theory (from the names: Derjarguin-Landau-Verwey-Overbeek) or XDLVO, which include traditional approach of the electric double layer (EDL), surfaces attraction forces or London-van der Waals (LvdW), esteric forces and hydrophobic forces, additionally considering another forces in colloidal system, like molecular repulsion or Born Repulsion and Acid-Base (AB) chemical function forces from Lewis.

Keywords: mathematical modeling; direct filtration; colloidal theory; XDLVO theory. 


\section{Introdução}

O uso do termo colóide, do grego cola, foi originalmente atribuído a Thomas Graham, em 1861, ao que até então era chamado de pseudosolução. Um sistema coloidal consiste em um sistema de duas fases principais: a dispersa (sólida, líquida ou gasosa), distribuída em uma segunda, a fase contínua ou meio disperso (sólida, líquida ou gasosa). Alguns arranjos estruturais e associações de colóides estão divididos em: sistemas dispersos, associação de colóides, colóides hidrofilicos, redes coloidais e complexos coloidais.

A associação de colóides, bastante comum em sistemas biológicos como rios, lagos e represas, é uma estrutura mais complexa de colóides agregados, formando unidades maiores em um sistema dinâmico e termodinâmico dependente da temperatura, concentração, composição do solvente e estrutura química específica.

Em uma abordagem tanto cinética quanto termodinâmica da estabilidade coloidal, são consideradas as forças de interação entre colóides, bem como as forças intermoleculares e eletrocinéticas. Tais forças podem ser classificadas em seis categorias:

- forças da dupla camada elétrica (DCE);

- forças de atração de superfície ou London-van der Waals (LvdW ou vdW);

- forças estéricas;

- força hidrofóbica;

- força molecular de repulsão ou repulsão de Born;

- forças de hidratação e de solvatação.

No tratamento de águas, os colóides hidrofóbicos constituem o objeto principal de estudo, em virtude das necessidades específicas que este tipo de colóide exige para a sua remoção do veículo e objeto principal do tratamento: a água.

Mesmo após a desestabilização eletrostática proporcionada pela coagulação e a posterior formação de flocos na floculação, ainda se trata de um sistema coloidal, do ponto de vista físico-químico, complexo.

Este trabalho objetivou a utilização da modelação matemática microscópica da filtração para as situações pré e pós-desestabilização eletrostática pela ação do coagulante sulfato de alumínio utilizando-se a teoria coloidal, além de análise e determinação de perfis de energia de interação dos sistemas coloidais na água de estudo contendo caulinita durante as etapas de floculação e filtração.

\section{Modelagem matemática}

Muitos autores utilizam a abordagem pelo balanço de forças ou de energia potencial para determinar os mecanismos de aderênciae desprendimento atuantes no sistema partícula-partícula e partícula-coletor, constituindo-se em uma abordagem bastante utilizada atualmente para o estudo da filtração (CHRISTENSON et al., 1990; SHARMA et al., 1992; AMIRTHARAJAH e RAVEENDRAN, 1993; RAVEENDRAN e AMIRTHARAJAH, 1995; BAI e TIEN, 1996; BAI e TIEN, 1997; BERGENDHAL e GRASSO, 1998; LEVEAU, 2001. MAHMOOD et al., 2001).
Dos aspectos mais importantes nesta abordagem, seja pela caracterização das forças ou pelo balanço da energia de interação (interações de superfície) atuantes no sistema partícula-coletor e/ou partícula-partícula, destaca-se a incorporação do efeito das condições químicas ao mesmo tempo em que se consideram as forças hidrodinâmicas existentes na filtração.

Segundo Bai e Tien (1997), os diâmetros da partícula e do coletor, $d_{p}$ e $d_{c}$, respectivamente, têm diferença de ordem de grandeza geralmente de pelo menos duas vezes. Entretanto, usualmente a diferença é bem maior. Considere o diâmetro do coletor (grão de areia) que pode ser cerca de 1 mil vezes ou mais o diâmetro da partícula. Desta forma, considerar a partícula uma esfera e a superfície do coletor um plano - separados por uma fina camada líquida de espessura d, também chamada de distância de separação de equilíbrio - pode ser avaliada como uma aproximação razoável.

Podem-se dividir as forças existentes num sistema composto por partícula-coletor em três categorias: de origem hidrodinâmica: $F_{\mathrm{A}} \mathrm{e}$ $F_{E}$ que são, respectivamente, força de arrasto $(N)$ e força de empuxo ou elevação $(\mathrm{N})$; forças de aderência: $F^{\mathrm{vdW}}$ e $F^{\mathrm{DCE}}$, respectivamente força de London - van der Waals (N) e força da dupla camada elétrica $(\mathrm{N})$; e força de origem mecânica: $F_{\mathrm{F}}$ que é a força de atrito $(\mathrm{N})$. A força de arrasto $\left(F_{\mathrm{A}}\right)$ de origem hidrodinâmica é produzida pela ação do fluido em deslocamento na direção tangencial ao longo do plano do coletor, ao passo que a força de empuxo $\left(F_{E}\right)$ atua na direção normal ao plano do coletor. A força de aderência de London - van der Waals $\left(F^{\mathrm{vdw}}\right)$, que age na direção normal ao plano do coletor, é sempre considerada de caráter atrativa e tem origem na interação do tipo dipolo-dipolo presente nas moléculas (teoria DLVO).

A força da dupla camada elétrica $\left(F^{\mathrm{DCE}}\right)$ também age na direção normal ao plano do coletor e usualmente é de repulsão em se tratando de filtração de água (teoria DLVO). A força de atrito $\left(F_{\mathrm{F}}\right)$ age na mesma direção, em sentido contrário à força de arrasto, tangencialmente ao plano do coletor. Já as mecânicas atuantes, tanto as de origem hidrodinâmica quanto a de atrito, devem atuar em um equilíbrio dinâmico tal que a força de atrito $\left(F_{F}\right)$ seja maior que a força de arrasto $\left(F_{\mathrm{A}}\right)$ para que a partícula permaneça aderida. Do contrário, a força de empuxo ou elevação $\left(F_{E}\right)$ causará o desprendimento da partícula do coletor.

Raveendran e Amirtharajah (1995) e Jegatheesan e Vigneswaran (2000) quantificaram a influência da dupla camada elétrica com a energia e a correspondente força entre uma esfera (partícula) e uma superfície plana (coletor), conforme as Equações 1 e 2, na forma de diferenças:

$\Delta G^{D C E}=32 \pi \varepsilon_{a} d_{p}\left(\frac{k T}{Z e}\right)^{2} \tanh \left(\frac{Z e \psi_{o, 1}}{4 k T}\right) \tanh \left(\frac{Z e \psi_{o, 2}}{4 k T}\right) \exp (-k \delta)$
$F^{D C E}=-32 \pi \varepsilon_{a} k d_{p}\left(\frac{k T}{Z e}\right)^{2} \tanh \left(\frac{Z e \psi_{o, 1}}{4 k T}\right) \tanh \left(\frac{Z e \psi_{o, 2}}{4 k T}\right) \exp (-k \delta)$

Considera-se $\delta$ a distância entre a esfera e a superfície assumidamente plana do coletor ( $\mathrm{m}$ ); $Z$ a valência do íon (adimensional); $Y_{\mathrm{o}, \mathrm{i}} \mathrm{O}$ 
potencial da superfície $i(\mathrm{~V}) ; e_{\mathrm{a}}=\varepsilon \varepsilon_{0}$ o coeficiente de permissividade da solução; $\varepsilon$ e $\varepsilon_{0}$ o coeficiente de permissividade da água e a absoluta, respectivamente; $k$ a constante de Boltzmann, igual a $1,380658.10^{-23} \mathrm{~J} \cdot \mathrm{K}^{-1}$; e a carga do elétron, igual a $1,602177 \cdot 10^{-19} \mathrm{C}$; T a temperatura absoluta em Kelvin (K); e $\kappa$ o parâmetro de Debye-Huckel ou simplesmente constante de Debye igual a $\kappa=\sqrt{\frac{e^{2} n_{o} Z^{2}}{\varepsilon_{a} k T}} \quad(\mathrm{~m})$ ou $\kappa=\sqrt{\frac{2 F^{2} I .10^{3}}{\varepsilon_{a} R T}}$ $\left(\mathrm{m}^{-1}\right)$, em que $n_{0}$ é o número de íons presentes, I é a força iônica do sistema (água + partículas + coletores) e F é a constante de Faraday, igual a $9,648531 \cdot 10^{4} \mathrm{C} \cdot \mathrm{mol}^{-1}$.

Caso seja utilizada a geometria de duas esferas na interação entre duas partículas de diâmetros $d_{\mathrm{p} 1}$ e $d_{\mathrm{p} 2}$, nas equações 1 e $2, d_{\mathrm{p}}$ deve ser substituído por $\left[\frac{d_{p 1} d_{p 2}}{2\left(d_{p 1}+d_{p 2}\right)}\right]$.

Outra geometria possível para o caso da caulinita, um tipo de argila utilizada na água de estudo deste trabalho, no específico caso da interação caulinita-caulinita, é a de dois cilindros paralelos longitudinalmente, ambos com diâmetro $d_{\mathrm{pc}}$ e comprimento l. Esta configuração foi obtida por Mahmood et al. (2001), conforme a Equação 3.

$$
F^{D C E}=-32 \varepsilon_{a} l \kappa \sqrt{\pi \kappa \frac{d_{p c}}{2}}\left(\frac{k T}{Z e}\right)^{2}\left[\tanh \left(\frac{Z e \psi_{o, 1}}{4 k T}\right)\right]^{2} \exp (-\kappa \delta)
$$

A região interna da dupla camada elétrica (camada de Stern ou camada de Helmholtz) se divide em duas regiões bem definidas, sendo que uma consiste na presença de íons não hidratados - camada de Stern - e a outra, camada de íons hidratados - camada de Helmholtz.

Fora da camada de Helmholtz existe a denominada camada difusa - ou camada Gouy-Chapman. O potencial Zeta ( $\zeta)$, que substitui a medida do potencial de superfície para fins práticos, em medidas experimentais, na verdade é uma medida do potencial elétrico existente na camada líquida do plano de cisalhamento que corresponde à região interna da camada de Helmoltz.

Para quantificar a energia e força de interação de van der Waals, Leveau (2001) encontrou as Equações 4 e 5 para o caso da geometria plana, para o coletor, e esférica para a partícula, em que a distância de separação é muito menor que o diâmetro da partícula $\left(d<d_{p}\right)$

$$
\begin{aligned}
& \Delta G^{v d W}=-\frac{H d_{p}}{12 \delta}\left[1-\frac{5,32 \delta}{\lambda_{w}} \ln \left(1+\frac{\lambda_{w}}{5,32 \delta}\right)\right] \\
& F^{v d W}=\frac{H d_{p}}{12 \delta^{2}}\left(\frac{5,32 \delta}{\lambda_{w}}+1\right)^{-1}
\end{aligned}
$$

Nelas, $H$ é a constante de Hamaker específica para cada caso (características físicas do fluido e das partículas e coletores) (J) e $l_{w}$ é o comprimento de onda da luz espalhada entre as partículas (m).

Caso seja utilizada a geometria de duas esferas, para o caso da interação entre duas partículas de diâmetros $d_{\mathrm{p} 1}$ e $d_{\mathrm{p} 2}$ nas Equações 4 e $5, d_{p}$ deve ser substituído por $\left[\frac{d_{p 1} d_{p 2}}{2\left(d_{p 1}+d_{p 2}\right)}\right]$
Mahmood et al. (2001) consideraram a forma integrada para o cálculo da energia e da força atrativa de van der Waals, com base na abordagem de Hamaker, para a geometria de dois planos de espessura desprezível - Equações 6 e 7 - bem como a de dois cilindros paralelos longitudinalmente, ambos com diâmetro $d_{\mathrm{pc}}$ e comprimento $l$. Tais geometrias são comuns para o caso de partículas de caulinita, conforme Equações 8 e 9 .

$$
\begin{aligned}
& \Delta G^{v d W}=-\frac{H}{12 \pi \delta^{2}} \\
& F^{v d W}=-\frac{H}{6 \pi \delta^{3}} \\
& \Delta G^{v d W}=-\frac{H l}{12 \sqrt{2 \delta^{3 / 2}}}\left[\frac{d_{p c 1} d_{p c 2}}{2\left(d_{p c 1}+d_{p c 2}\right)}\right]^{1 / 2} \\
& F^{v d W}=-\frac{H}{2 \sqrt{2}}\left(\frac{l}{d_{p c}^{2}}\right)\left(\frac{d_{p c}}{2 \delta}\right)^{5 / 2}
\end{aligned}
$$

A energia e a força de repulsão de Born foram quantificadas por Raveendran e Amirtharajah (1995), que as apresentam como a interação entre a partícula assumidamente esférica e o plano do coletor, conforme as Equações 10 a 12.

$$
\Delta G^{\text {Born }}=\frac{H \chi^{6}}{7.560}\left[\frac{4 d_{p}+\delta}{\left(d_{p}+\delta\right)^{7}}+\frac{3 d_{p}-\delta}{\delta^{7}}\right]
$$

Quando a distância de separação é muito menor que o diâmetro da partícula $\left(d<d_{p}\right)$, então a energia de interação $(J)$ e a respectiva força de Born (N) se tornam como demonstrado nas Equações 11 e 12, em que c é o chamado diâmetro de colisão na ordem de 0,5 a 1,0 nm.

$$
\begin{gathered}
\Delta G^{\text {Born }}=\frac{H \chi^{6} d_{p}}{2.520 \delta^{7}} \\
F^{\text {Born }}=-\frac{H \chi^{6} d_{p}}{360 \delta^{8}}
\end{gathered}
$$

Para o caso da interação entre partículas de geometria assumidamente esféricas, Feke et al. (1984) desenvolveram a Equação 13 para a energia de repulsão de Born. Nela, $R$ (m) é a distância de separação entre os centros das esferas; $n$ (número real) é chamado de grau de força de repulsão entre partículas macroscópicas quando se calcula o potencial interatômico, podendo assumir qualquer valor real, exceto $n=7,6,5,4,3$ ou 2 (mais comumente se utiliza $n=12$ ); e $\alpha_{d}$ é um adimensional e expressa a razão entre diâmetros $==>\alpha_{d}=\frac{d_{p 2}}{d_{p 1}}$.

$$
\Delta G^{B o m}=\frac{2 H d_{p}}{R}\left(\frac{2 \chi}{d_{p}}\right)^{n-6}\left[\frac{(n-8) !}{(n-2) !}\right]\left[\begin{array}{l}
\frac{-R^{2}-(n-5)\left(\alpha_{d}-1\right) R-(n-6)\left(\alpha_{d}^{2}-(n-5) \alpha_{d}+1\right)}{\left(R-1+\alpha_{d}\right)^{n-5}}+ \\
\frac{-R^{2}+(n-5)\left(\alpha_{d}-1\right) R-(n-6)\left(\alpha_{d}^{2}-(n-5) \alpha_{d}+1\right)}{\left(R+1+\alpha_{d}\right)^{n-5}}+ \\
\frac{R^{2}+(n-5)\left(\alpha_{d}+1\right) R+(n-6)\left(\alpha_{d}^{2}+(n-5) \alpha_{d}+1\right)}{\left(R+1+\alpha_{d}\right)^{n-5}}+ \\
\frac{R^{2}-(n-5)\left(\alpha_{d}+1\right) R+(n-6)\left(\alpha_{p}^{2}+(n-5) \alpha_{d}+1\right)}{\left(R-1-\alpha_{d}\right)^{n-5}}
\end{array}\right\}
$$


Para o caso de duas esferas de mesmo diâmetro, o resultado é a Equação 14, ao passo que a força pode ser determinada pela Equação 15.

$$
\begin{aligned}
& \Delta G^{\text {Borm }}=H\left(\frac{2 \chi}{d_{p}}\right)^{6} \frac{1}{37800 R}\left[\frac{R^{2}-14 R+54}{(R-2)^{7}}+\frac{-2 R^{2}+60}{R^{7}}+\frac{R^{2}+14 R+54}{(R+2)^{7}}\right](14) \\
& F^{\text {Borm }}=\frac{2 H}{360 d_{p}} \cdot\left(\frac{2 \chi}{d_{p}}\right)^{6} \cdot \frac{1}{\left(2 \delta / d_{p}\right)^{8}}(15)
\end{aligned}
$$

As Equações 16 e 17 apresentam, respectivamente, a energia e a força de repulsão de Born, desenvolvidas por Mahmood et al. (2001), na geometria plano e plano, a exemplo do que ocorre entre partículas de caulinita, ao passo que as Equações 18 e 19 são as simplificadas por este autor para a geometria de dois cilindros (geometria também assemelhada para as partículas de caulinita) paralelos longitudinalmente, ambos com diâmetro $d_{\mathrm{pc}}$ e comprimento $l$.

$$
\begin{aligned}
& \Delta G^{\text {Born }}=\frac{H \chi^{6}}{360 \pi \delta^{8}} \\
& F^{\text {Born }}=-\frac{H \chi^{6}}{45 \pi \delta^{9}} \\
& \Delta G^{\text {Born }}=\frac{H \chi^{6} l d_{p c}}{360 \pi \delta^{8}} \\
& F^{\text {Born }}=-\frac{H \chi^{6} l d_{p c}}{45 \pi \delta^{9}}
\end{aligned}
$$

A força de hidratação é muito pequena em comparação à força atrativa de van der Waals ou à força repulsiva de Born, bem como quando comparada com a exercida pela dupla camada, e pode, portanto, ser desprezada (FEKE et al., 1984; MAHMOOD et al., 2001).

A energia total ( $D G^{\text {Total }}$, advinda da interação física entre as superfícies das partículas coloidais existentes na água e representada pela Equação 20, é expressa em termos da soma das parcelas de energia $\left(\mathrm{J} / \mathrm{m}^{2}\right)$ : energia de atração de van der Waals, energia de repulsão de Born e da dupla camada elétrica, a qual será chamada neste trabalho de teoria DLVO + Born.

$$
\Delta G^{\text {Total }}=\Delta G^{v d W}+\Delta G^{\text {Born }}+\Delta G^{D C E}
$$

A teoria DLVO modificada, ou XDLVO, inclui as forças de outras origens no cálculo do balanço de forças, a saber: repulsão molecular, chamada de repulsão de Born, e a força oriunda das funções químicas Ácido e Base (AB) de Lewis (HOEK e AGARWAL, 2006).

Para uma geometria esférica para a partícula e plana para a superfície do coletor, pode-se quantificar a energia $\mathrm{AB}$ e a respectiva força atuante conforme as Equações 21 e 22, em que $\lambda_{A B}$ é o comprimento de onda da luz espalhada para interação $A B$ entre 0,2 e $1 \mathrm{~nm}$ - Bergendhal e Grasso (2000) encontraram valores de $\lambda_{\mathrm{AB}}$ entre 0,6 e $1 \mathrm{~nm} ; \Delta G_{\delta_{0}}^{A B}$ é a variação de energia mínima (para a mínima distância de separação $\delta_{0}$ ) de Lewis AB entre duas superfícies planas $\left(\mathrm{mJ} . \mathrm{m}^{-2}\right)$.

$$
\begin{aligned}
& \Delta G^{A B}=\pi \cdot d_{p} \cdot \lambda_{A B} \cdot \Delta G_{\delta_{0}}^{A B} \cdot \exp \left(\frac{\delta_{0}-\delta}{\lambda_{A B}}\right) \\
& F^{A B}=\pi \cdot d_{p} \Delta G_{\delta_{0}}^{A B} \cdot \exp \left(\frac{\delta_{0}-\delta}{\lambda_{A B}}\right)
\end{aligned}
$$

Seu valor, entretanto pode ser calculado pela mensuração das tensões superficiais, conforme a Equação 23, na qual $\gamma_{i}^{+}$é a tensão superficial do elétron do material receptor i $\left(\mathrm{mJ} \cdot \mathrm{m}^{-2}\right)$ e $\gamma_{\mathrm{i}}$ - é a tensão superficial do elétron do material doador i $\left(\mathrm{mJ} \cdot \mathrm{m}^{-2}\right)$.

$\Delta G_{\delta_{0}}^{A B}=2\left[\sqrt{\gamma_{3}^{+}} \cdot\left(\sqrt{\gamma_{1}^{-}}+\sqrt{\gamma_{2}^{-}}-\sqrt{\gamma_{3}^{-}}\right)+\sqrt{\gamma_{3}^{-}} \cdot\left(\sqrt{\gamma_{1}^{+}}+\sqrt{\gamma_{2}^{+}}-\sqrt{\gamma_{3}^{+}}\right)-\sqrt{\gamma_{1}^{+} \cdot \gamma_{2}^{-}}-\sqrt{\gamma_{1}^{-} \cdot \gamma_{2}^{+}}\right]$

Para o caso de duas esferas, a energia $A B$ e a respectiva força atuante são dadas pelas Equações 24 e 25, ao passo que as Equações 26 e 27 apresentam as obtidas por este autor para a geometria de dois cilindros (geometria também assemelhada para as partículas de caulinita, na interação entre si) paralelos longitudinalmente, ambos com diâmetro $d_{\mathrm{pc}}$ e comprimento $l$.

$$
\begin{aligned}
& \Delta G^{A B}=\frac{\pi}{2} \cdot d_{p} \cdot \lambda_{A B} \cdot \Delta G_{\delta_{0}}^{A B} \cdot \exp \left(\frac{\delta_{0}-\delta}{\lambda_{A B}}\right) \\
& F^{A B}=\frac{\pi}{2} \cdot d_{p} \Delta G_{\delta_{0}}^{A B} \cdot \exp \left(\frac{\delta_{0}-\delta}{\lambda_{A B}}\right) \\
& \Delta G^{A B}=\frac{l}{4} \cdot \sqrt{\pi \lambda_{A B} d_{p c}} \cdot \lambda_{A B} \cdot \Delta G_{\delta_{0}}^{A B} \cdot \exp \left(\frac{\delta_{0}-\delta}{\lambda_{A B}}\right) \\
& F^{A B}=\frac{l}{4} \cdot \sqrt{\pi \lambda_{A B} d_{p c}} \cdot \Delta G_{\delta_{0}}^{A B} \cdot \exp \left(\frac{\delta_{0}-\delta}{\lambda_{A B}}\right)
\end{aligned}
$$

A nova abordagem para a teoria XDLVO para a DCE inclui a contribuição qualitativa e, até certo ponto, quantitativa das forças acima descritas. Neste caso, para a teoria XDLVO, a energia total resulta da soma de todas as contribuições apresentadas nesta seção: energia de atração de van der Waals, energia de repulsão de Born, energia da dupla camada elétrica e energia $\mathrm{AB}$ de Lewis, conforme a Equação 28.

$\Delta G^{\text {Total }}=\Delta G^{v d W}+\Delta G^{B o r n}+\Delta G^{D C E}+\Delta G^{A B}$

A concentração que marca a mudança da estabilidade para a instabilidade, ou vice-versa, é frequentemente chamada de concentração crítica de coagulação (CCC), que depende da valência do íon e independe do raio da partícula. Tal independência advém da condição arbitrária para cálculo de potencial resultante nulo.

\section{Materiais e Métodos}

Para a determinação dos perfis de energia de atração e repulsão entre os sistemas e complexos coloidais foram feitas medidas experimentais em carreiras de filtração direta em um 
A
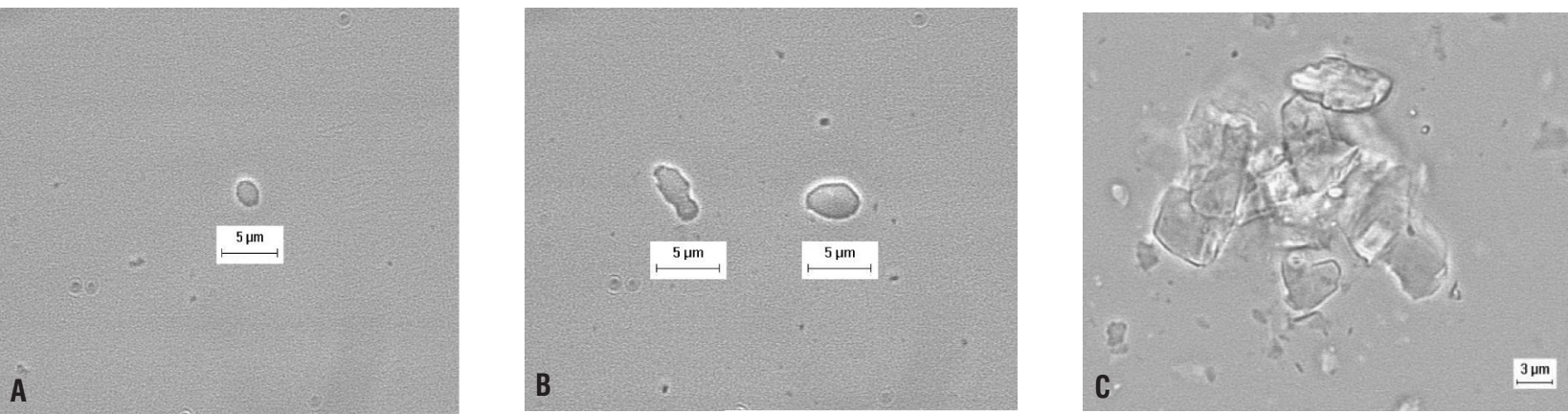

Figura 1 - Partículas de argila ao microscópio óptico: (A) partícula de caulinita encontrada na parte sobrenadante da solução de água com caulinita; (B) partícula de caulinita encontrada na solução "mãe"; (C) "cluster" de partículas de caulinita comumente encontradas em solução de água com caulinita (solução "mãe").

sistema de dupla filtração para as seguintes situações: anterior (partículas primárias) e posterior à utilização do agente coagulante (sulfato de alumínio) após a coagulação e floculação em meio poroso.

A Figura 1 mostra as imagens de partículas de argila ao microscópio óptico e a Figura 2 apresenta a instalação piloto na qual foram obtidos os dados experimentais utilizados para alimentar o modelo pela teoria coloidal. O sistema é composto por dois filtros ascendentes de areia grossa (FAAG), montados em paralelo seguidos de um filtro rápido descendente (FRD).

Os materiais granulares utilizados nos filtros ascendentes têm como características gerais: tamanho dos grãos de 1,19 a 3,36 mm; tamanho efetivo de 1,41 mm; coeficiente de desuniformidade de 1,42; e espessura da camada de 1,4 m. A caracterização detalhada do meio filtrante do filtro ascendente de areia grossa é apresentada na Tabela 1.

Foram preparadas duas amostras de água: a I e a II, com turbidez de aproximadamente 100 e $300 \mathrm{uT}$ (unidades de Turbidez), respectivamente, obtidas com o sobrenadante da suspensão de caulinita misturada com água de poço.

O equipamento para a determinação do potencial zeta foi o Zetâmetro Malvern, modelo Zetamaster particle eletrophoresis analyser, que utiliza espectroscopia de correlação de fótons.

O equipamento para a captura de imagens conta com uma câmera acoplada a um microscópio que as envia a um microcomputador equipado com um software ambiente Windows para a aquisição e tratamento de imagens.

Foi empregada a microscopia ótica do Laboratório de Processos Biológicos (LPB) - Departamento de Hidráulica e Saneamento Escola de Engenharia de São Carlos /Universidade de São Paulo para a visualização do tamanho e forma das partículas de caulinita encontradas na água de estudo, conforme a Figura 1. A Tabela 2 apresenta as demais características físico-químicas da caulinita utilizada para o preparo da água de estudo.

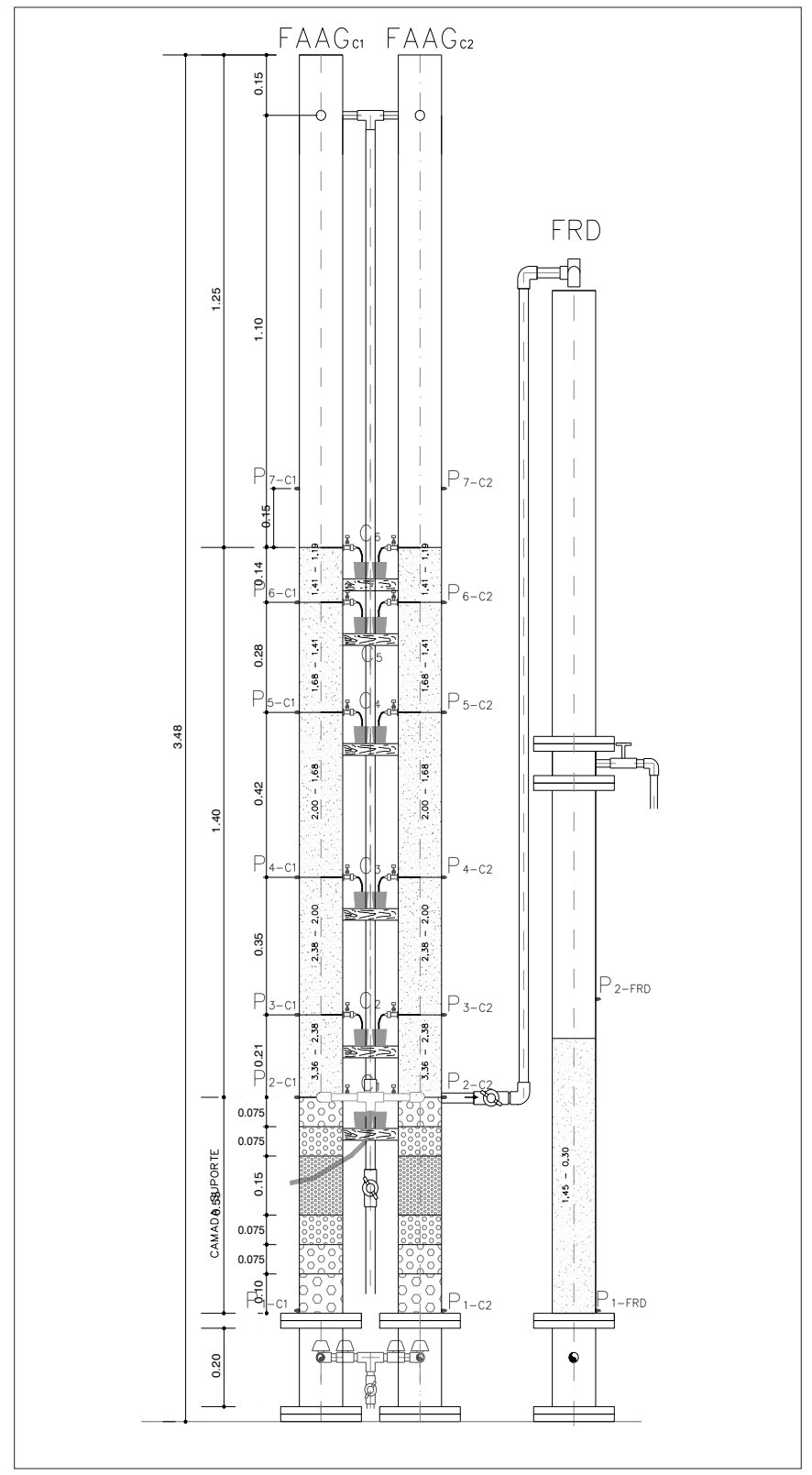

Figura 2 - Detalhe da instalação piloto de dupla filtração (medição em metro) Fonte: Botari e Di Bernardo (2007). 
Tabela 1 - Camada suporte e meio filtrante do filtro ascendente de areia grossa.

\begin{tabular}{|c|c|c|c|c|c|}
\hline Camada & Subcamada & Tamanho $(\mathrm{mm})$ & Espessura (cm) & Esfericidade & Porosidade \\
\hline 6 (topo) & & 1,19 a 1,41 & 14,0 & 0,81 & \\
\hline 5 & & 1,41 a 1,68 & 28,0 & 0,77 & \\
\hline 4 & - & 1,68 a 2,00 & 42,0 & 0,79 & 0,39 \\
\hline 2 & & 2,38 a 3,36 & 21,0 & 0,77 & \\
\hline \multirow{5}{*}{1 (suporte) } & 1 & 12,70 a 19,0 & 7,5 & \multirow{5}{*}{0,80} & \multirow{5}{*}{0,40} \\
\hline & 2 & 6,40 a 12,70 & 7,5 & & \\
\hline & 4 & 6,40 a 12,70 & 7,5 & & \\
\hline & 5 & 12,70 a 19,00 & 7,5 & & \\
\hline & 6 (fundo) & 19,00 a 25,40 & 10,0 & & \\
\hline
\end{tabular}

Fonte: Botari (2007).

Tabela 2 - Características gerais da caulinita utilizada para o preparo das águas de estudo (dados fornecidos pelo fabricante).

\begin{tabular}{|c|c|}
\hline \multicolumn{2}{|l|}{ Propriedades físicas } \\
\hline Nome comercial & Caulim micronizado \\
\hline Aspecto & Pó fino \\
\hline Cor & Branca \\
\hline Massa específica do grão $\left(\mathrm{g} \cdot \mathrm{cm}^{-3}\right)$ & $2,60 \pm 0,05$ \\
\hline Massa específica aparente solta $\left(\mathrm{g} \cdot \mathrm{cm}^{-3}\right)$ & $0,47 \pm 0,02$ \\
\hline Massa específica aparente compactada $\left(\mathrm{g} \mathrm{cm}^{-3}\right)$ & $0,57 \pm 0,02$ \\
\hline Umidade (\% máxima) & 1,00 \\
\hline Esfericidade & 0,58 \\
\hline \multicolumn{2}{|c|}{ Composição (porcentagem expressa em óxidos) } \\
\hline $\mathrm{SiO}_{2}$ (Dióxido de Silício) & 47,30 \\
\hline $\mathrm{Al}_{2} \mathrm{O}_{3}$ (Óxido de Alumínio) & 36,30 \\
\hline $\mathrm{Fe}_{2} \mathrm{O}_{3}$ (Óxido de Ferro) & 0,63 \\
\hline $\mathrm{TiO}_{2}$ (Dióxido de Titânio) & 0,51 \\
\hline CaO (Óxido de Cálcio) & $<0,05$ \\
\hline MgO (Óxido de Magnésio) & $<0,10$ \\
\hline MnO (Óxido de Manganês) & $<0,01$ \\
\hline $\mathrm{Na}_{2} \mathrm{O}$ (Óxido de Sódio) & 0,52 \\
\hline $\mathrm{K}_{2} \mathrm{O}$ (Óxido de Potássio) & 9,30 \\
\hline
\end{tabular}

Fonte: Botari (2007).

\section{Resultados e Discussões}

\section{Constante de Hamaker}

A constante de Hamaker para a interação entre os componentes do sistema (água + caulinita + coletor) foi estimada matematicamente utilizando-se as constantes de Hamaker $(H)$ determinadas segundo as propriedades individuais dos materiais na seguinte combinação: $H_{132}=H_{12}+H_{33}-H_{13}-H_{23}$. Segundo Israelachvili (1992), esta combinação pode ser aproximada conforme a Equação 29, em que $H$ é a constante de Hamaker e os índices 1, 2 e 3 são referentes aos elementos constituintes do sistema: coletor, partícula e água, respectivamente.

$$
H_{132} \approx\left(H_{12}^{1 / 2}-H_{33}^{1 / 2}\right) \cdot\left(H_{22}^{1 / 2}-H_{33}^{1 / 2}\right)
$$

Os valores das constantes de Hamaker determinadas segundo as propriedades individuais dos materiais foram os seguintes:

- Coletor (areia): $H_{11}=4,04 \cdot 10^{-20} \mathrm{~J}$ (BERGENDHAL e GRASSO, 1999)

- Partícula (caulinita em meio aquoso): $H_{22}=4,70 \cdot 10^{-20} \mathrm{~J}$ (Berka e Rice, 2004)

- Água: $H_{33}=3,70.10^{-20} \mathrm{~J}$ (BERGENDHAL e GRASSO, 1999)

\section{Tensões superficiais}

Os valores das tensões superficiais são requeridos para o cálculo da energia de interação Ácido-Base de Lewis (AB), conforme apresentado pela Equação 28. Os utilizados neste trabalho, bem como as referências das quais foram extraídos, são apresentados na Tabela 3. Tais valores, tanto para a areia quanto para a caulinita, podem variar bastante em função das condições de preparação, da forma de medição e do tipo de material das amostras (BERGENDHAL e GRASSO, 1999; JACOBS et al., 2007; CHEN e FLURY, 2005).

\section{Demais parâmetros}

- Diâmetro de Colisão $\chi$ (Repulsão de Born)

O valor do diâmetro de colisão $\chi$ é usualmente considerado entre 0,5 e $1 \mathrm{~nm}$, segundo Bergendhal e Grasso (1999). Considerou-se neste trabalho $0,5 \mathrm{~nm}$

- Comprimento de onda (decaimento) $l_{\mathrm{AB}}$ (Ácido-Base de Lewis $-\mathrm{AB})$

Para Israelachvili (1992), o comprimento de onda $\mathrm{l}_{\mathrm{AB}}$ (decaimento) para interação AB é considerado entre 1 e 2 nm. Van Oss (1994) 
considerou $\mathrm{l}_{\mathrm{AB}}$ entre 0,2 e $1 \mathrm{~nm}$ e recomendou 0,6 $\mathrm{nm}$, valor adotado neste trabalho.

- Distância de aproximação $\delta_{0}$ (Ácido-Base de Lewis - AB)

Van Oss (1994) considerou valores para a distância de aproximação $\delta_{o}$ entre 0,2 e $1 \mathrm{~nm}$ e recomendou $0,16 \mathrm{~nm}$, adotado neste estudo.

A Tabela 4 apresenta um sumário dos valores adotados e utilizados neste trabalho para a modelação matemática dos perfis de energia de interação no sistema formado por água, caulinita e areia.

\section{Perfis de energia de interação em função da distância de separação}

Os diferentes arranjos de interação entre superfícies e as diversas geometrias adotadas para partículas e coletor para a modelação matemática pela teoria coloidal propostos neste trabalho são elencados na Tabela 5. As letras apresentadas nas legendas dos gráficos dos perfis de energia de interação entre as superfícies em função da distância apresentadas neste trabalho estarão doravante relacionadas com os arranjos de interação entre superfícies, geometria e dimensões mostrados na Tabela 5 e na Figura 3.

\section{Situação de leito limpo}

Os perfis de energia existentes na interação entre partícula - partícula e partícula - coletor nas geometrias e situações mostradas na Tabela 5 e Figura 3 em função da distância, e que são apresentadas nesta e nas próximas seções, têm legendas abreviadas e que representam: "dg" variação ou delta de energia; "F" força; "DCE" dupla camada elétrica; "VdW" van der Waals; "Born" Born; "AB" Ácido-Base de Lewis; "DLVO" teoria DLVO - Derjarguin-Landau-Verwey-Overbeek; "XDLVO" teoria DLVO estendida (XDLVO).

As Tabelas 6 e 7 apresentam os mínimos primários e secundários de energia, se existirem, e as distâncias correspondentes pela aplicação das teorias DLVO, DLVO + Born (proposta neste trabalho) e XDLVO para diferentes situações em que se fez a modelação matemática pela teoria coloidal na condição de leito limpo, conforme Equação 30 e as já mencionadas 20 e 28, respectivamente.

$\Delta G^{\text {Total }}=\Delta G^{v d W}+\Delta G^{D C E}$

Além dos somatórios para a energia, propõe-se o somatório para o balanço de forças utilizando-se o conceito das teorias DLVO, DLVO + Born e XDLVO, conforme as Equações 31, 32 e 33, respectivamente, em que $\Delta F$ se refere à variação da força $(n N)$ em função da distância de separação $(\boldsymbol{\delta})(\mathrm{nm})$ ao passo que os índices se referem às forças a serem consideradas no balanço; e o índice "Total" está ligado à somatória. Devem-se compatibilizar as unidades das parcelas antes de efetuar a soma das Equações 31 a 33, bem como ponderar
Tabela 3 - Valores de tensões superficiais (Energia AB) e suas respectivas referências.

\begin{tabular}{|c|c|c|c|}
\hline Material & $\gamma^{+}\left(m J . m^{-2}\right)$ & $\gamma^{-}\left(\mathrm{mJ} . \mathrm{m}^{-2}\right)$ & Referências \\
\hline Água & 25,50 & 25,50 & Van Oss (1994) \\
\hline Coletor (areia) & 3,85 & 20,40 & Jacobs et al. (2007) \\
\hline Partículas (caulinita) & 0,00 & 32,40 & Chen e Flury (2005) \\
\hline
\end{tabular}

Tabela 4 - Sumário dos parâmetros físico-químicos e seus respectivos valores adotados ou mensurados utilizados na modelação matemática dos perfis de energia de interação entre caulinita e areia (coletor).

\begin{tabular}{|c|c|c|}
\hline & Parâmetros físico-químicos & $\begin{array}{l}\text { Valores adotados } \\
\text { ou mensurados }\end{array}$ \\
\hline \multirow{3}{*}{ Sistema } & $\mathrm{pH}^{\mathrm{a}, \mathrm{b}}$ & 7,7 \\
\hline & & \\
\hline & Temperatura ${ }^{a, b}$ & $25^{\circ} \mathrm{C}$ \\
\hline \multirow{4}{*}{$\begin{array}{l}\text { Partículas } \\
\text { (caulinita em sus- } \\
\text { pensão aquosa) }\end{array}$} & Diâmetro & $3 \mu \mathrm{m}$ \\
\hline & $\begin{array}{l}\xi-\text { potencial zeta }^{\mathrm{a}} \\
\xi-\text { potencial zeta }^{\mathrm{b}}\end{array}$ & $\begin{array}{l}-10 \mathrm{mV} \\
-0,2 \mathrm{mV}\end{array}$ \\
\hline & Constante de Hamaker & $\mathrm{H}_{33}=6,6 \cdot 10^{-20} \mathrm{~J}$ \\
\hline & Tensão superficial & $\begin{array}{c}\gamma_{3}^{+}=0 \mathrm{~mJ} \cdot \mathrm{m}^{-2} \\
\gamma_{3}^{-}=5,9 \mathrm{~mJ} \cdot \mathrm{m}^{-2}\end{array}$ \\
\hline \multirow{3}{*}{$\begin{array}{l}\text { Meio poroso } \\
\text { (areia em meio } \\
\text { aquoso) }\end{array}$} & $\begin{array}{l}\zeta-\text { potencial zeta }^{c} \\
\zeta-\text { potencial zeta }^{b}\end{array}$ & $\begin{array}{l}-25 \mathrm{mV} \\
-0,2 \mathrm{mV}\end{array}$ \\
\hline & Constante de Hamaker & $\mathrm{H}_{11}=6 \cdot 34 \cdot 10^{-20} \mathrm{~J}$ \\
\hline & Tensão superficial & $\begin{array}{c}\gamma_{1}^{+}=2,3 \mathrm{~mJ} \cdot \mathrm{m}^{-2} \\
\gamma_{1}^{-}=26,8 \mathrm{~mJ} \cdot \mathrm{m}^{-2}\end{array}$ \\
\hline \multirow{3}{*}{ Parâmetros } & Diâmetro de colisão $\chi$ & $0,5 \mathrm{~nm}$ \\
\hline & $\begin{array}{l}\text { Comprimento de onda } \\
\text { (decaimento) } \lambda_{\mathrm{AB}}\end{array}$ & $0,6 \mathrm{~nm}$ \\
\hline & Distância de aproximação $\delta_{0}$ & $0,16 \mathrm{~nm}$ \\
\hline
\end{tabular}

aMedido neste trabalho - condição de leito limpo; bMedido neste trabalho - condição de leito com depósito - carreira de filtração direta (dupla filtração); cJacobs, et al. (2007) condição de leito limpo.

Tabela 5 - Geometrias representativas para coletor e partícula e as interações modeladas neste trabalho.

\begin{tabular}{|c|c|c|}
\hline & Geometria e dimensões (m) & $\begin{array}{l}\text { Arranjos de } \\
\text { interação }\end{array}$ \\
\hline \multirow{3}{*}{ Partículas (P) } & Cilíndrica (C) $\left(d_{p c}=2,1 \cdot 10^{-7} ; I=2,1 \cdot 10^{-6}\right)$ & $P-P$ \\
\hline & Plana (F) (dimensões infinitas*) & $P-P$ \\
\hline & Esférica $(E)\left(d_{p}=2,1.10^{-7}\right)$ & $P-P$ e A-P \\
\hline Coletor (A) & Plana (F) (dimensões infinitas) & $A-P$ \\
\hline
\end{tabular}

*Aproximação utilizando superposição linear (LSA - do inglês Linear Superposition Approximation) para o caso da Dupla Camada Elétrica(DCE); a aproximação de Hamaker para o caso de Born e Lifshitz-Van der Waals e aproximação da integração de Derjaguin (DI - do inglês Derjaguin Integration) para AB - Ácido-Base de Lewis. 
pelas áreas a serem consideradas, se assim for o caso, as parcelas nas Equações 20, 28 e 30, antes de efetuar a soma.

$\Delta F^{\text {Total }}=\Delta F^{v d W}+\Delta F^{D C E}$

$\Delta F^{\text {Total }}=\Delta F^{v d W}+\Delta F^{\text {Born }}+\Delta F^{D C E}$

$$
\Delta F^{\text {Total }}=\Delta F^{v d W}+\Delta F^{B o r n}+\Delta F^{D C E}+\Delta F^{A B}
$$

\section{Situação de leito com depósito}

Perfis de energia existentes na interação entre partícula - partícula e partícula - coletor nas geometrias e situações mostradas na Tabela 5 e Figura 3 em função da distância, conforme consta na seção anterior, são apresentados aqui na condição de leito com depósito. Não serão demonstrados todos os perfis detalhados, mas apenas aqueles com a aplicação dos modelos DLVO, DLVO + Born e XDLVO para diferentes situações em que se fez a modelação matemática pela teoria coloidal na condição de leito com depósito.

As Tabelas 8 e 9 apresentam os mínimos primários e secundários de energia, se existirem, e as distâncias correspondentes pela aplicação das teorias DLVO, DLVO + Born e XDLVO para diferentes situações em que se fez a modelação matemática pela teoria coloidal na condição de leito com depósito. As palavras "não" e "origem", nas Tabelas 6 a 9, significam que não

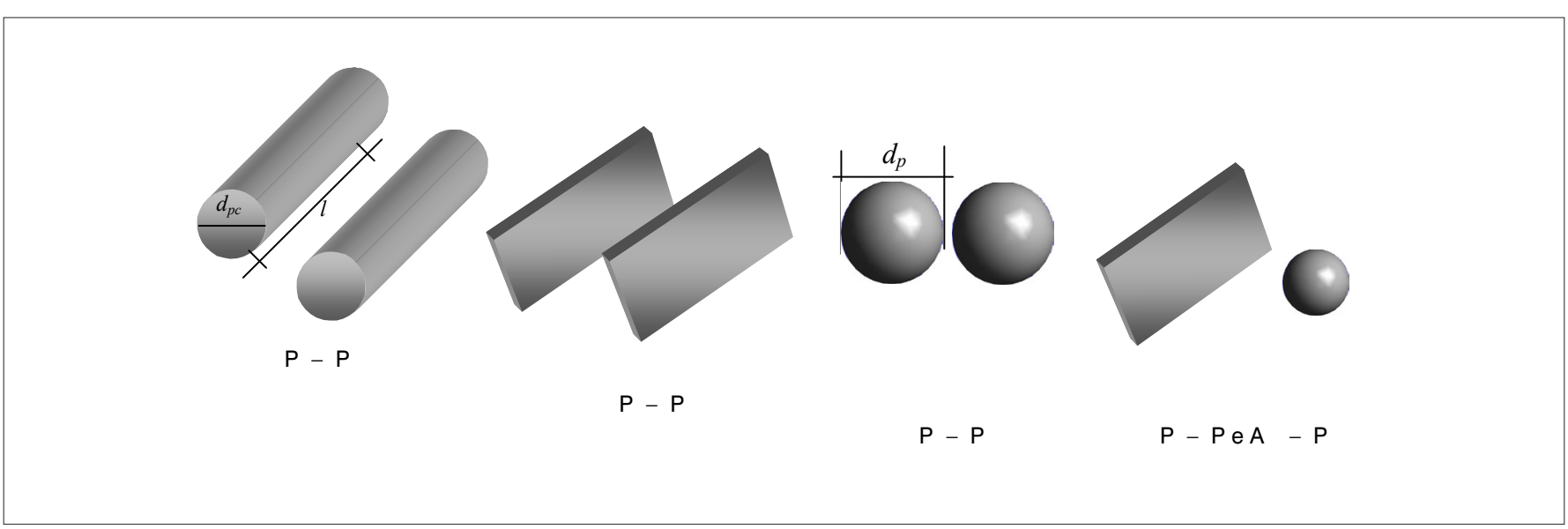

Figura 3 - Arranjos de interação entre superfícies, geometrias e dimensões para a modelação matemática pela teoria coloidal apresentadas na Tabela 5.

Tabela 6 - Mínimos primários e secundários de energia e as distâncias correspondentes obtidos pela modelação matemática pela teoria coloidal na condição de leito limpo - geometria placa - esfera.

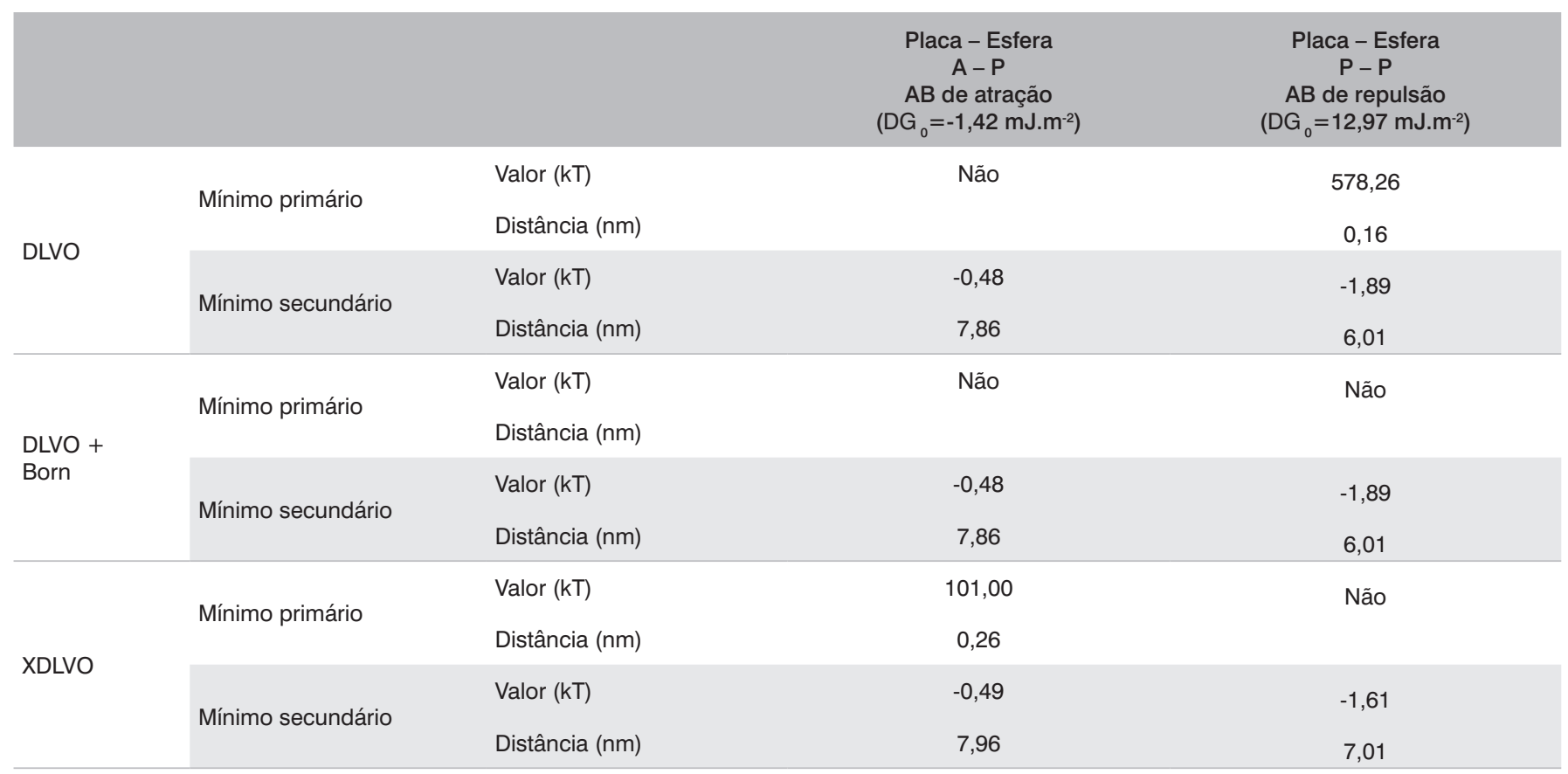


Tabela 7 - Mínimos primários e secundários de energia e as distâncias correspondentes obtidos pela modelação matemática pela teoria coloidal na condição de leito limpo - nas demais geometrias.

\begin{tabular}{|c|c|c|c|c|c|}
\hline & & & & Cilindro - Cilindro & \\
\hline & & & Placa - Placa & $\begin{array}{c}\mathrm{P}-\mathrm{P} \\
\mathrm{AB} \text { de repulsão } \\
\left(\mathrm{DG}_{0}=12,97 \mathrm{~mJ} \cdot \mathrm{m}^{-2}\right)\end{array}$ & Esfera - Esfera \\
\hline & Mínimo primário & $\begin{array}{l}\text { Valor }(\mathrm{kT}) \\
\text { Distância (nm) }\end{array}$ & Não & Não & $\begin{array}{c}289,13 \\
0,16\end{array}$ \\
\hline DLVO & Mínimo secundário & $\begin{array}{l}\text { Valor (kT) } \\
\text { Distância (nm) }\end{array}$ & Não & Não & $\begin{array}{l}-0,94 \\
6,01\end{array}$ \\
\hline DLVO + & Mínimo primário & $\begin{array}{l}\text { Valor }(\mathrm{kT}) \\
\text { Distância }(\mathrm{nm})\end{array}$ & Não & Não & Não \\
\hline Born & Mínimo secundário & $\begin{array}{l}\text { Valor }(\mathrm{kT}) \\
\text { Distância }(\mathrm{nm})\end{array}$ & Não & Não & $\begin{array}{l}-0,94 \\
6,01\end{array}$ \\
\hline XDLV & Mínimo primário & $\begin{array}{l}\text { Valor }(\mathrm{kT}) \\
\text { Distância (nm) }\end{array}$ & Não & Não & Não \\
\hline & Mínimo secundário & $\begin{array}{l}\text { Valor }(\mathrm{kT}) \\
\text { Distância }(\mathrm{nm})\end{array}$ & Não & Não & $\begin{array}{r}-0,81 \\
6,69\end{array}$ \\
\hline
\end{tabular}

Tabela 8 - Mínimos primários e secundários de energia e as distâncias correspondentes obtidos pela modelação matemática pela teoria coloidal na condição de leito com depósito - geometria placa - esfera.

\begin{tabular}{|c|c|c|c|c|}
\hline & & & $\begin{array}{c}\text { Placa - Esfera } \\
\text { A - P } \\
\text { AB de atração } \\
\left(\mathrm{DG}_{0}=-1,42 \mathrm{~mJ} \cdot \mathrm{m}^{-2}\right)\end{array}$ & $\begin{array}{c}\text { Placa - Esfera } \\
P-P \\
A B \text { de repulsão } \\
\left(D_{0}=12,97 \mathrm{~mJ} \cdot \mathrm{m}^{-2}\right)\end{array}$ \\
\hline \multirow{3}{*}{ DLVO } & \multirow{2}{*}{ Mínimo primário } & Valor $(k T)$ & $-894,98$ & \multirow{2}{*}{ Não } \\
\hline & & Distância (nm) & 0,01 & \\
\hline & Mínimo secundário & $\begin{array}{l}\text { Valor }(\mathrm{kT}) \\
\text { Distância }(\mathrm{nm})\end{array}$ & Não & Não \\
\hline \multirow{3}{*}{$\begin{array}{l}\text { DLVO + } \\
\text { Born }\end{array}$} & \multirow{2}{*}{ Mínimo primário } & Valor $(\mathrm{kT})$ & $-24,53$ & $-69,47$ \\
\hline & & Distância (nm) & 0,31 & 0,31 \\
\hline & Mínimo secundário & $\begin{array}{l}\text { Valor }(\mathrm{kT}) \\
\text { Distância }(\mathrm{nm})\end{array}$ & Não & Não \\
\hline \multirow{3}{*}{ XDLVO } & \multirow{2}{*}{ Mínimo primário } & Valor (kT) & $-1.258,39$ & \multirow{2}{*}{ Não } \\
\hline & & Distância (nm) & 0,26 & \\
\hline & Mínimo secundário & $\begin{array}{l}\text { Valor }(\mathrm{kT}) \\
\text { Distância }(\mathrm{nm})\end{array}$ & Não & Não \\
\hline
\end{tabular}

Tabela 9 - Mínimos primários e secundários de energia e as distâncias correspondentes obtidos pela modelação matemática pela teoria coloidal na condição de leito com depósito - nas demais geometrias.

\begin{tabular}{|c|c|c|c|c|c|}
\hline & & & & Cilindro - Cilindro & \\
\hline & & & Placa - Placa & $\begin{array}{c}\mathrm{P}-\mathrm{P} \\
\mathrm{AB} \text { de repulsão } \\
\left(\mathrm{DG}_{0}=12,97 \mathrm{~mJ} \cdot \mathrm{m}^{-2}\right)\end{array}$ & Esfera - Esfera \\
\hline \multirow{4}{*}{ DLVO } & \multirow{2}{*}{ Mínimo primário } & Valor (kT) & \multirow{2}{*}{ Não } & $-1,4.10^{-7}$ & $-1265,41$ \\
\hline & & Distância (nm) & & 7,71 & 0,01 \\
\hline & \multirow{2}{*}{ Mínimo secundário } & Valor $(k T)$ & \multirow{2}{*}{ Não } & \multirow{2}{*}{ Não } & \multirow{2}{*}{ Não } \\
\hline & & Distância (nm) & & & \\
\hline \multirow{4}{*}{$\begin{array}{l}\text { DLVO + } \\
\text { Born }\end{array}$} & \multirow{2}{*}{ Mínimo primário } & Valor $(\mathrm{kT})$ & \multirow{2}{*}{ Não } & \multirow{2}{*}{ Não } & 0,04 \\
\hline & & Distância (nm) & & & origem \\
\hline & \multirow{2}{*}{ Mínimo secundário } & Valor $(\mathrm{kT})$ & \multirow{2}{*}{ Não } & \multirow{2}{*}{ Não } & $-34,74$ \\
\hline & & Distância (nm) & & & 0,31 \\
\hline \multirow{4}{*}{ XDLVO } & \multirow{2}{*}{ Mínimo primário } & Valor $(k T)$ & \multirow{2}{*}{ Não } & \multirow{2}{*}{ Não } & 8015,21 \\
\hline & & Distância (nm) & & & Origem \\
\hline & \multirow{2}{*}{ Mínimo secundário } & Valor (kT) & \multirow{2}{*}{ Não } & \multirow{2}{*}{ Não } & $-0,89$ \\
\hline & & Distância (nm) & & & 6,56 \\
\hline
\end{tabular}


ocorrem mínimos perceptíveis na escala (por exemplo, comportamento assintótico) ou ocorre na origem dos eixos cartesianos, respectivamente.

Deve-se ressaltar que a condição de potencial zeta do sistema (coletor + partícula + água) foi alterada pela adição de coagulante sulfato de alumínio na dosagem (situação de CCC), o que implica na compressão da DCE. Tal fato resulta na reversão dos potenciais: anteriormente prevalecentemente de repulsão agora prevalecentemente de atração.

A interação determinada pela força Ácido-Base de Lewis (AB) é influenciada principalmente pela energia para mínima distância de separação $\left(\Delta G_{\delta_{0}}^{A B}\right)$ e pelo comprimento de onda de decaimento $l_{\mathrm{AB}}$. O efeito provocado pela variação do valor da energia para mínima distância de separação ( $\Delta G_{\delta_{0}}^{A B}$ ), para o caso da interação entre coletor e partícula na geometria esfera - placa plana, pode ser verificado nas Figuras 4 e 5, nas condições de leito limpo e com depósito, respectivamente.

Na Figura 4 verifica-se que a teoria DLVO apresenta a maior força repulsiva, inexistindo-se um mínimo primário. O mesmo ocorre com a teoria DLVO + Born. Embora o mesmo fenômeno aconteça para a aplicação da teoria XDLVO, pode-se verificar que há uma pequena depleção na curva de seu perfil $\left(\Delta G_{\delta_{0}}^{A B}=-0,1 \mathrm{~mJ} \cdot \mathrm{m}^{-2}\right)$, conforme a Figura 5.

Observa-se, nas demais curvas para a teoria XDLVO, incremento cada vez maior da depleção na curva de seu perfil, com a variação no valor da energia para mínima distância de separação $\left(\Delta G_{\delta_{0}}^{A B}\right.$ ), conforme Figura 5. Evidentemente, aumentando-se o valor da energia para mínima distância de separação de atração (caso de $\Delta G_{\delta_{0}}^{A B}=-0,5 \mathrm{~mJ} \cdot \mathrm{m}^{-2}$ ) maior (em módulo) se torna o valor da mínima energia primária de atração $(-758,5 \mathrm{kT}$ para distância de separação $0,26 \mathrm{~nm}$ ), conforme a Figura 5. É interessante, entretanto, verificar que, mesmo para o maior valor de energia para mínima distância de separação repulsiva (caso de $\Delta G_{\delta_{0}}^{A B}=0,5 \mathrm{~mJ} \cdot \mathrm{m}^{-2}$ ), a depleção na curva de seu perfil ainda é maior que a obtida pela teoria DLVO.

Desconsiderando-se a energia de interação $\mathrm{AB}$ na composição do perfil de energia em função da distância de separação pela teoria DLVO + Born, pode-se verificar, mesmo para a condição de potencial zeta próximo de zero, e na condição de leito com depósito, a existência de um mínimo primário pequeno. Para a teoria DLVO na condição de leito com depósito, verifica-se o maior valor (em módulo) da energia mínima primária de atração $(-895$ kT) em uma distância de separação de apenas 0,01 nm.

Comparando-se os perfis existentes na Figura 4 e os da Figura 5 pode-se verificar claramente o deslocamento das curvas de uma situação de repulsão entre o coletor e a partícula para uma situação de atração, com as curvas mais próximas do eixo das abscissas. A existência, ainda que de pequenos valores de mínimos primários, é observada para a situação de leito com depósito para as teorias DLVO + Born e XDLVO (ambas para um valor de $\Delta G_{\delta_{0}}^{A B}=-0,1 \mathrm{~mJ} \cdot \mathrm{m}^{-2}$ ) entre
0,26 e 0,30 nm de distância de separação entre coletor e partícula, conforme Figura 5.

Os valores de energia para mínima distância de separação $\left(\Delta G_{\delta_{0}}^{A B}\right)$ para as interações entre coletor e partícula no meio aquoso e entre partícula e partícula no meio aquoso, calculados pela Equação (23) e utilizados neste trabalho foram de $\Delta G_{\delta_{0}}^{A B}=-1,4175 \mathrm{~mJ} \cdot \mathrm{m}^{-2} \mathrm{e}$ $\Delta G_{\delta_{0}}^{A B}=-12,9748 \mathrm{~mJ} \cdot \mathrm{m}^{-2}$, respectivamente.

De forma geral, a magnitude da força $A B$ desempenhou fundamental papel na determinação do desenvolvimento do perfil de forças ou de energia quando considerado, como no caso da teoria XDLVO, permitindo aumento considerável (em módulo) no pico de mínima primário de energia. Neste trabalho não são apresentados os perfis de forças em função do espaço reduzido.

As Figuras 6 e 7 demonstram o efeito da geometria do coletor e da partícula no desenvolvimento dos perfis de energia nas interações apresentadas na Figura 3 (exceto cilindro/cilindro) nas situações de leito limpo e com depósito, respectivamente.

Nas legendas da Figuras 6 e 7 observam-se as letras maiúsculas "AP" e "PP", que representam as interações entre Coletor (A - Areia) e Partícula ( $\mathrm{P}$ - Partícula de caulinita), respectivamente, seguidas das geometrias denominadas "EE" e "EF" que representam a geometria esfera/ esfera (E - Esfera) e esfera/placa plana (do inglês Flat - F). A Figura 6 oferece a situação de leito limpo, no qual se pode verificar a clara preponderância da energia da DCE na resultante de repulsão encontrada nas interações para todas as geometrias consideradas. A maior energia de repulsão da DCE é observada para a geometria de esfera e placa plana na interação coletor/partícula, ao passo que a menor é observada na geometria esfera/esfera para o mesmo tipo de interação.

A Figura 6 apresenta a situação de leito com depósito, no qual se pode verificar a redução drástica no valor da energia da DCE, resultando na condição de atração nas interações para todas as geometrias consideradas, em virtude da mudança na CCC pela presença do agente coagulante - sulfato de alumínio.

Um aspecto interessante a ser ressaltado é o valor muito elevado da energia para a repulsão de Born. Para a magnitude fraca desta força de interação, os modelos para a repulsão de Born para as geometrias consideradas mostraram-se inadequados. Tal incoerência pode ser verificada não apenas na magnitude da energia de repulsão de Born, mas também pelo caráter de atração que se pode verificar na geometria de esfera e placa plana na interação coletor/partícula, conforme Figuras 6 e 7.

Em virtude da forte influência das forças de interação entre superfícies proporcionadas pelo modelo Ácido-Base de Lewis (AB) como para a repulsão de Born, talvez sejam necessárias medidas mais realísticas para os valores dos parâmetros de tais modelos. A força hidrofóbica de natureza apolar, que permite às partículas se associarem umas às outras ao passo que o solvente polar (água) aprisionado entre as duas superfícies hidrofóbicas que reduzem o grau de liberdade do complexo formado, exerce uma influência não mensurada, e sua ausência no cálculo total tem efeito que se faz necessário aos modelos ora considerados. 


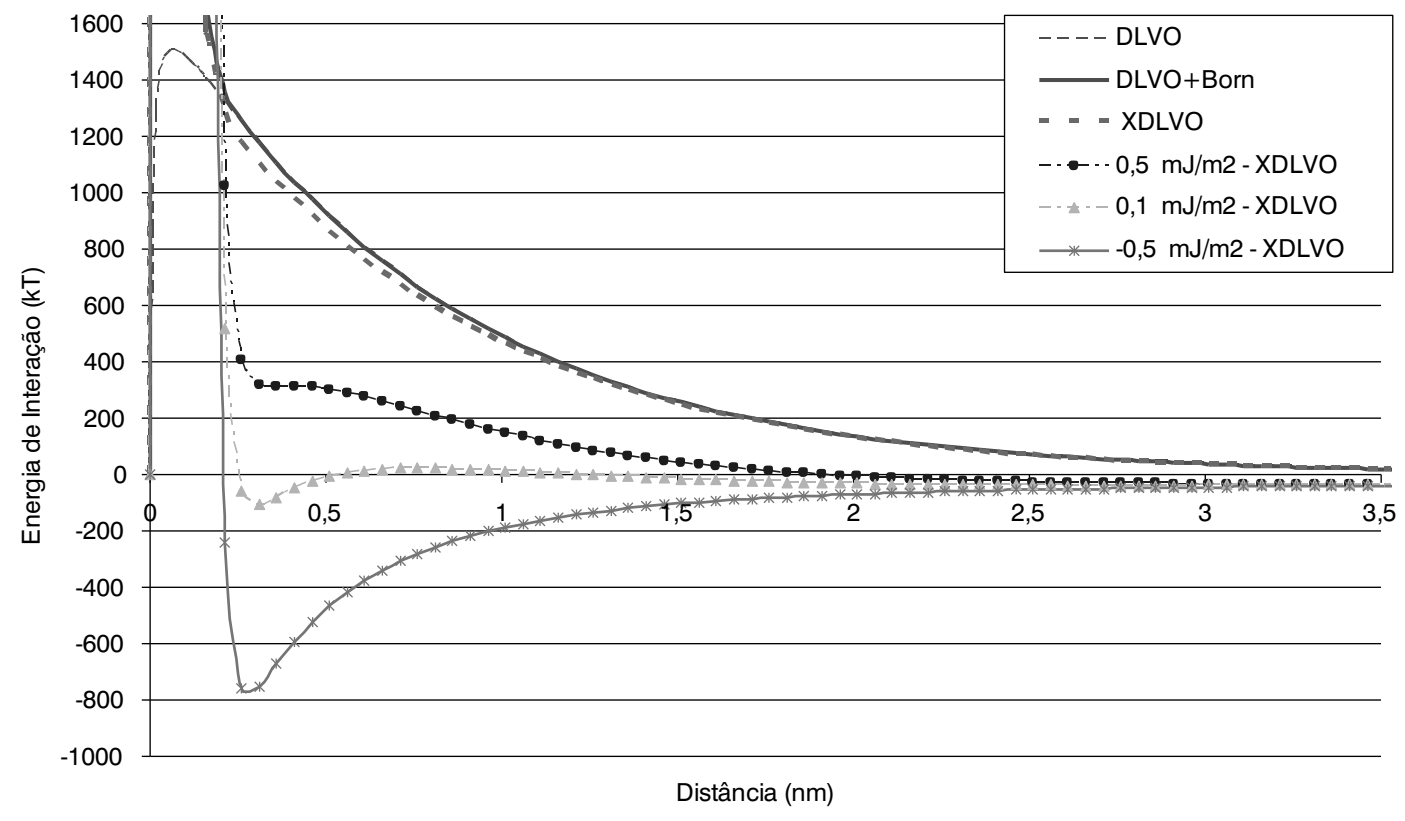

Figura 4 - Efeito do valor da energia para mínima distância de separação na interação $\mathrm{AB}\left(\Delta G_{\delta_{0}}^{A B}\right)$ - coletor/partícula - geometria esfera/placa plana situação de leito limpo.

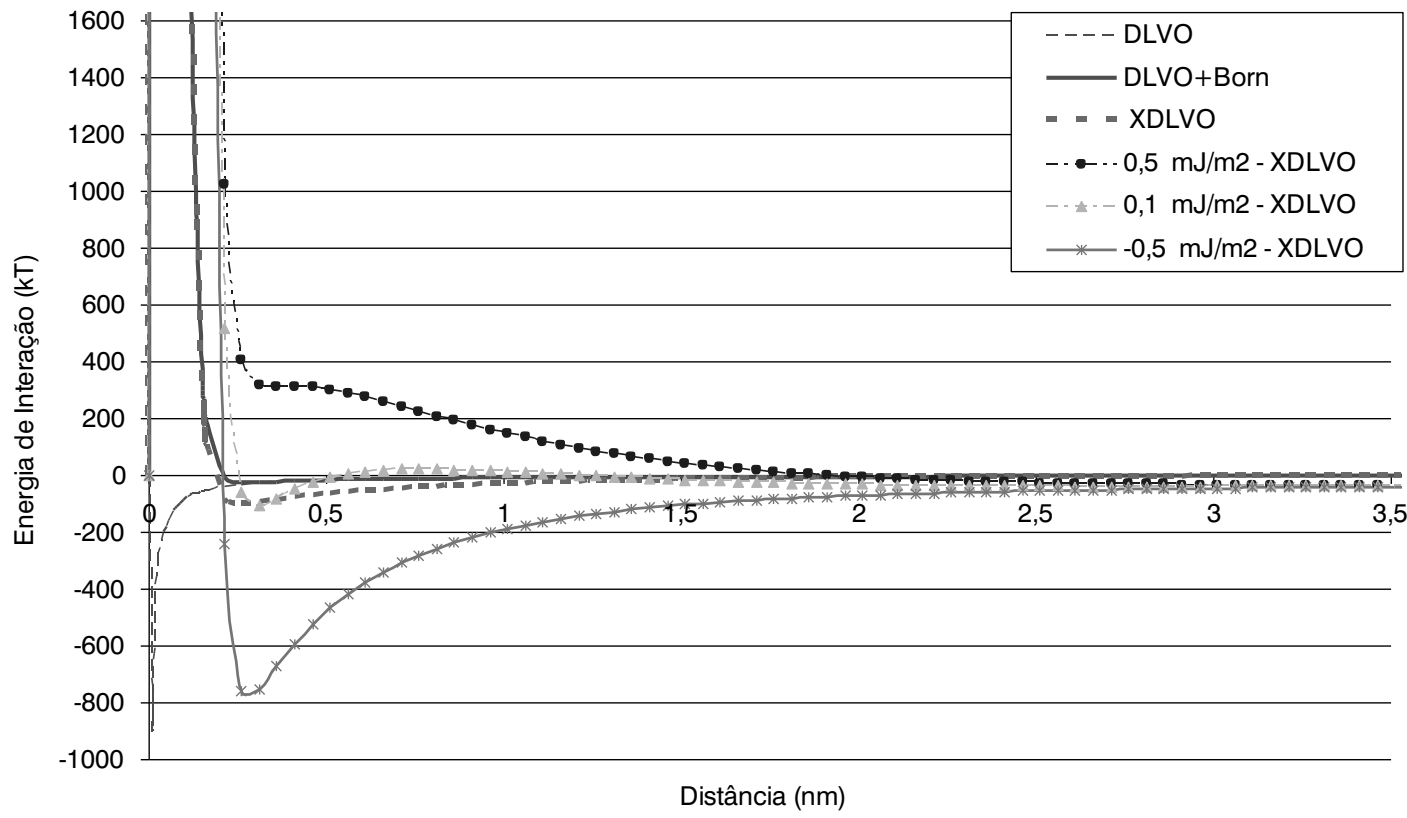

Figura 5 - Efeito do valor da energia para mínima distância de separação na interação $\mathrm{AB}\left(\Delta G_{\delta_{0}}^{A B}\right)$ - coletor/partícula - geometria esfera/placa plana situação de leito com depósito. 


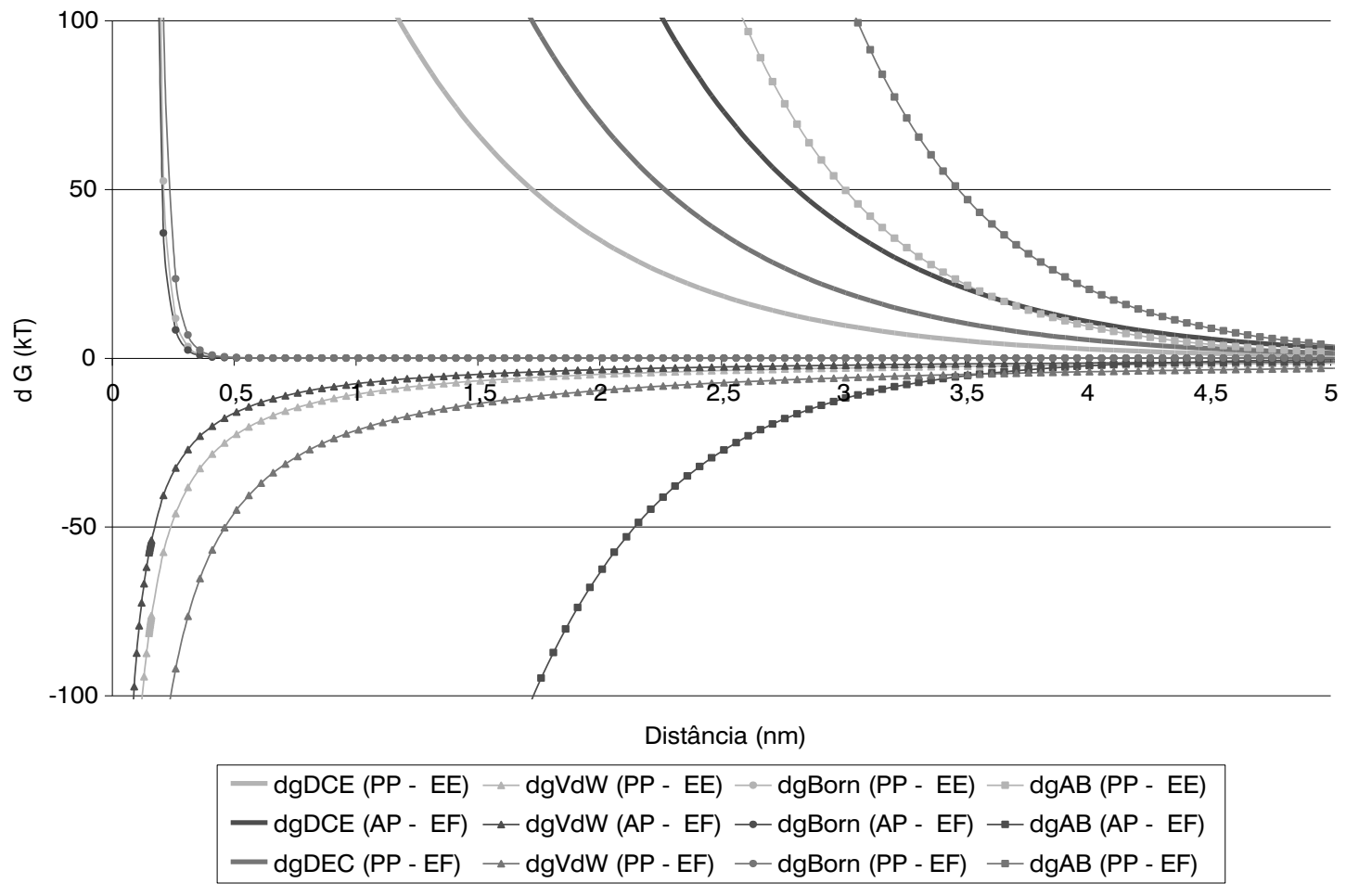

Figura 6 - Efeito da geometria do coletor e da partícula no desenvolvimento dos perfis de energia nas interações apresentadas na Figura 4 (exceto cilindro/ cilindro) - situação de leito limpo.

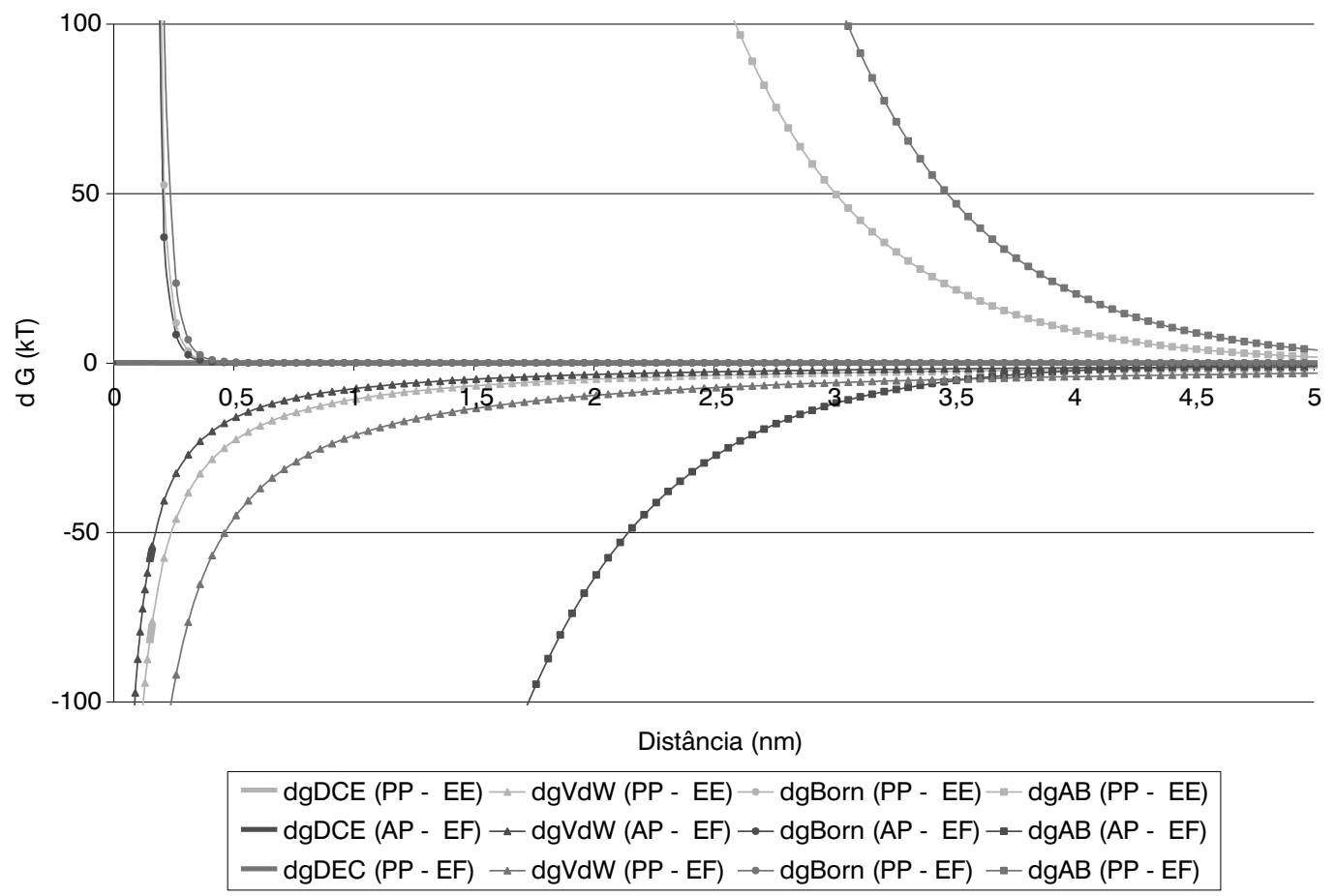

Figura 7 - Efeito da geometria do coletor e da partícula no desenvolvimento dos perfis de energia nas interações apresentadas na Figura 4 (exceto cilindro/ cilindro) - situação de leito com depósito. 
As forças de hidratação ou de solvatação, geradas pelo "empacotamento" das moléculas na interface entre elas e que modificam na intercamada entre as duas superfícies bem próximas umas das outras, também exerce uma influência não considerada nestes modelos e que pode explicar as incoerências.

\section{Conclusões}

As principais conclusões obtidas neste trabalho foram:

- A análise microscópica pela teoria XDLVO mostrou forte influência da parcela da força Ácido-Base de Lewis na composição geral de forças;
- Em função desta característica da teoria XDLVO, conclui-se haver necessidade de medidas experimentais, e não apenas teóricas, para a parcela da força Ácido-Base de Lewis na formulação da teoria XDLVO;

- As altas magnitudes das forças Ácido-Base de Lewis na formulação da teoria XDLVO provocam aumento excessivo nos níveis de energia primária do complexo partícula-grão coletor;

- Recomendam-se medidas experimentais reais para a efetiva validação dos cálculos pela teoria XDLVO para os parâmetros físicos de partículas e dos grãos coletores do meio filtrante, a saber: tensão superficial.

\section{Referências}

AMIRTHARAJAH, A.; RAVEENDRAN, P. (1993) Detachment of colloids from sediments and sand grains. Colloids and Surfaces A: Physicochemical and Engineering Aspects, v. 73, p. 221-7.

BAI, R.; TIEN, C. (1996) A new correlation for the initial filter coefficient under unfavorable surface interactions. Journal of Colloid and Interface Science, v. 179, n. 2, p. 631-4.

BAI, R.; TIEN, C. (1997) Particle detachment in deep bed filtration. Journal of Colloid and Interface Science, v. 186, n. 2, p. 307-17.

BERGENDAHL J.; GRASSO D. (1998) Colloid generation during batch leaching tests: mechanics of disaggregation. Colloids and Surfaces $A$ : Physicochemical and Engineering Aspects, v. 135, n. 1-3, p. 193-205.

BERGENDAHL, J.; GRASSO, D. (1999) Prediction of colloid detachment in a model porous media: thermodynamics. AlChE Journal, v. 45, n. 3, p. $475-84$

BERGENDAHL, J; GRASSO, D. (2000) Prediction of colloid detachment in a model porous media: hydrodynamics. Chemical Engineering Science, v. 55, n. 9, p. 1523-32.

BERKA, M.; RICE, J.A. (2004) Absolute aggregation rate constants in aggregation of kaolinite measured by simultaneous static and dynamic light scattering. Langmuir, v. 20, n. 15, p. 6152-7.

BOTARI, A. (2007) Modelação matemática da perda de carga e da remoção de turbidez e de partículas na filtração direta ascendente. 402 p. Tese (Doutorado) - Escola de Engenharia de São Carlos, Universidade de São Paulo, São Carlos.
BOTARI, A.; DI BERNARDO, L. (2009) Modelação da perda de carga na filtração direta ascendente em meio granular de areia grossa e pedregulho. Engenharia Sanitária e Ambiental, v. 14, n. 2 p. $245-56$

CHEN, G.; FLURY, M. (2005) Retention of mineral colloids in unsaturated porous media as related to their surface properties. Colloids and Surfaces A: Physicochemical and Engineering Aspects, v. 256, p. 207-16.

CHRISTENSON, H.K.; FANG, J.; NINHAM, B.W.; PARKER, J.L. (1990) Effect of divalent electrolyte on the hydrophobic attraction. The Journal of Physical Chemistry, v. 94, n. 21, p. 8004-6.

FEKE, D.L.; PRABHU, N.D.; MANN, J.A.; MANN, J.A. (1984) A formulation of the short-range repulsion between spherical colloidal particles. The Journal of Physical Chemistry, v. 88, n. 23, p. 5735-9.

HOEK, E.M.; AGARWAL, G.K. (2006) Extended DLVO interactions between spherical particles and rough surfaces. Journal of Colloid and Interface Science, v. 298, n. 1, p. 50-8.

ISRAELACHVILI, J. (1992) Intermolecular and surface forces, 2 ed. New York: NY Academic Press.

JACOBS, A.; LAFOLIE, F.; HERRY, J.M.; DEBROUX, M. (2007) Kinetic adhesion of bacterial cells to sand: cell surface properties and adhesion rate. Colloids and Surfaces B: Biointerfaces, v. 59, n. 1, p. 35-45.

JEGATHEESAN, V.; VIGNESWARAN, S. (2000) Transient stage deposition of submicron particles in deep bed filtration under unfavorable conditions. Water Research, v. 34, n. 7, p. 2119-31. 
LEVEAU, S. (2001) Deep bed filtration: analysis and modeling. $167 \mathrm{p}$. Thesis (Master of Science) - Georgia Institute of Technology, Atlanta, USA.

MAHMOOD, T.; AMIRTHARAJAH, A.; STURM, T.W.; DENNETT, K.E. (2001) A micromechanics approach for attachment and detachment of asymmetric colloidal particles. Colloids and Surfaces A: Physicochemical and Engineering Aspects, v. 177, p. 99-110.

RAVEENDRAN, P.; AMIRTHARAJAH, A. (1995) Role of short-range forces in particle detachment during filter backwashing. Journal of Environmental Engineering, v. 121, n. 12, p. 860-8.

SHARMA, M.M.; CHAMOUN, H.; SITA RAMASARMA, D.S.H.; SCHECHTER, R.S. (1992) Factors controlling the hydrodynamic detachment of particles from surfaces. Journal of Colloid and Interface Science, v. 149, n. 1, p. 121-34.

VAN OSS, C.J. (1994) Interfacial forces in aqueous media. New York. Marcel Dekker Inc. 